\title{
Minoxidil and its use in hair disorders: a review
}

This article was published in the following Dove Press journal:

Drug Design, Development and Therapy

\section{Poonkiat Suchonwanit \\ Sasima Thammarucha \\ Kanchana Leerunyakul}

Division of Dermatology, Department of Medicine, Faculty of Medicine,

Ramathibodi Hospital, Mahidol

University, Bangkok, Thailand
Correspondence: Poonkiat Suchonwanit Division of Dermatology, Department of Medicine, Faculty of Medicine,

Ramathibodi Hospital, Mahidol University,

270, Rama VI Road, Thung Phaya Thai,

Ratchathewi, Bangkok 10400, Thailand

Tel +662 20I II4I

Fax +6622011211

Email poonkiat@hotmail.com

\begin{abstract}
Minoxidil was first introduced as an antihypertensive medication and the discovery of its common adverse event, hypertrichosis, led to the development of a topical formulation for promoting hair growth. To date, topical minoxidil is the mainstay treatment for androgenetic alopecia and is used as an off-label treatment for other hair loss conditions. Despite its widespread application, the exact mechanism of action of minoxidil is still not fully understood. In this article, we aim to review and update current information on the pharmacology, mechanism of action, clinical efficacy, and adverse events of topical minoxidil.
\end{abstract}

Keywords: alopecia, beard, eyebrow, hair loss, hair shaft disorders, treatment

\section{Introduction}

Minoxidil was first introduced as an oral medication for the treatment of severe and recalcitrant hypertension in the 1970s. ${ }^{1}$ Coincidentally, physicians observed hair regrowth and generalized hypertrichosis in balding patients, which led to the development of a topical minoxidil formulation for treating androgenetic alopecia (AGA) first in male and then in female individuals. The $2 \%$ minoxidil solution was first launched in the market in 1986 , followed by the $5 \%$ solution in $1993 .^{2}$ Despite its global acceptance for over 30 years, the mechanism underlying the hair growthpromoting effects of minoxidil remains to be fully elucidated. We aimed to review and update critical clinical information on topical minoxidil including the pharmacology, mechanism of action, clinical efficacy, and adverse effects.

\section{Pharmacology of topical minoxidil}

Minoxidil is a piperidino-pyrimidine derivative, with the following chemical structure: 2,6-diamino-4-piperidinopyrimidine-1-oxide $\left(\mathrm{C}_{9} \mathrm{H}_{15} \mathrm{~N}_{5} \mathrm{O}\right)$ (Figure 1). ${ }^{2}$ Minoxidil solution (MS) contains inactive ingredients, including water, as well as ethanol and propylene glycol (PG), which are used as vehicles to enhance the solubility of minoxidil. ${ }^{3}$ PG facilitates efficient drug delivery into the hair follicles; however, its frequent induction of local irritation led to the development of a PG-free minoxidil foam (MF). The non-medical ingredients in the foam formulation include cetyl alcohol, stearyl alcohol, and butylated hydroxytoluene. ${ }^{4}$

Compared to MS, MF allows for increased delivery of the active ingredient to the target site and easy penetration of the drug with less irritation; hence, the US Food and Drug Administration (FDA) has granted approval for 5\% MF for the treatment of AGA. MF is also more convenient to use, because it dries quicker and spreads less to the peripheral region. ${ }^{5}$ 


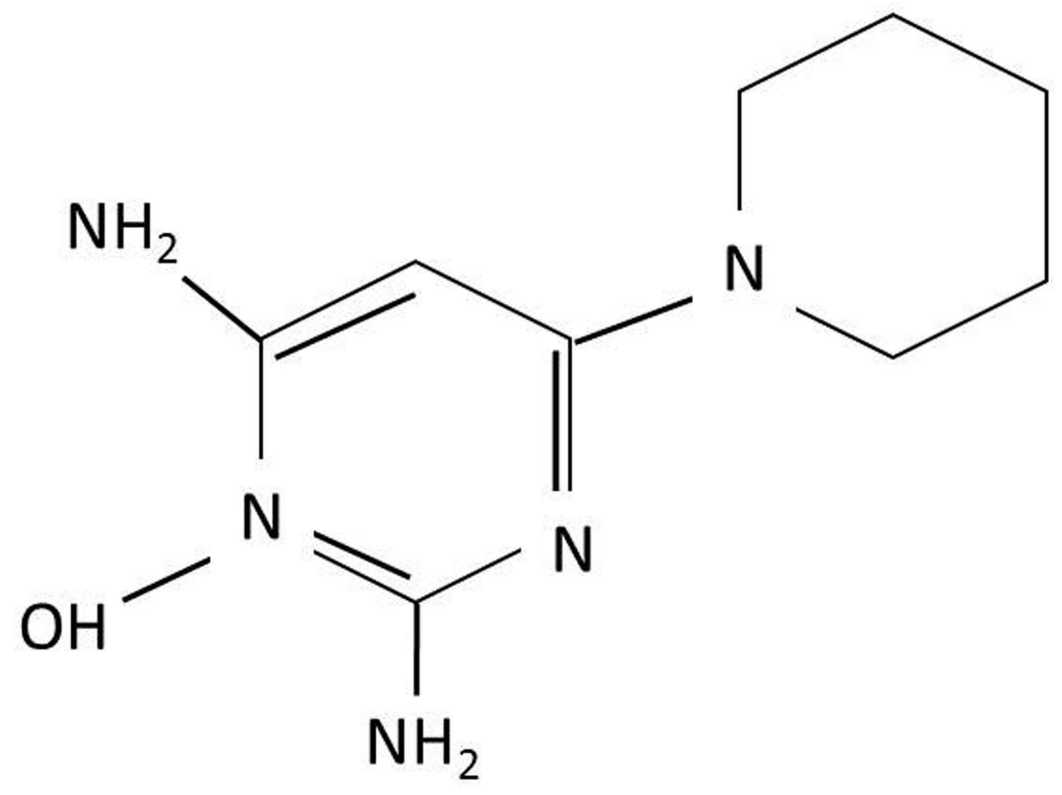

Figure I Chemical structure of minoxidil.

Minoxidil is a potent arteriolar vasodilator that opens potassium channels located on the smooth muscles of the peripheral artery, causing hyperpolarization of the cell membrane. ${ }^{6} \mathrm{Xu}$ et al suggested that $\mathrm{K}^{+}$-channel activity is necessary for progression to the $G_{1}$ stage of the cell cycle; therefore, it might play a key role in cell proliferation at the early stage. ${ }^{7}$ This theory was further supported by the results of an animal study in which minoxidil increased cellular DNA synthesis and enhanced cell proliferation. ${ }^{8}$

The positive effect of minoxidil on hair growth is mainly due to its metabolite, minoxidil sulfate, and the enzyme responsible for this conversion is sulfotransferase, which is located in hair follicles and varies in production among individuals. ${ }^{9}$ There are two phenol sulfotransferases responsible for minoxidil sulfation in the human scalp, and patients with higher enzyme activity responded better to topical minoxidil than those with lower enzyme activity did. It is noteworthy that there is no correlation between the serum or tissue concentration of minoxidil and hair growth. ${ }^{10}$ Salicylate and aspirin can inhibit sulfotransferase. A recent study showed that the follicular enzymatic activity decreased following 14 days of low-dose aspirin use. Thus, prior or concomitant use of aspirin decreases the clinical response to topical minoxidil. ${ }^{11}$

Pharmacokinetically, approximately $1.4 \%$ of topical minoxidil is absorbed through a normal scalp, while increased absorption is associated with drug concentration, frequency of drug application, and damage to the barrier function of the stratum corneum. Systemic absorption of topical minoxidil is less than $99 \%$ of the amount applied on the scalp. Minoxidil does not bind to plasma proteins or crosses the blood-brain barrier. Approximately $95 \%$ of the systemically absorbed drug and its metabolites are excreted via the kidney within 4 days. ${ }^{2,12}$

\section{Biological effects of minoxidil}

Minoxidil has been used for hair loss treatment for several decades. The medication affects follicular cells by enhancing hair growth and reducing hair loss. Termination of treatment results in progressive hair loss within 12 and 24 weeks. $^{2}$ Mori and Uno discovered that MS shortened the telogen phase to 1 to 2 days in treated rats compared to approximately 20 days in untreated rats. There was an increase in the rate of DNA synthesis in anagen bulbs, suggesting that minoxidil stimulated secondary hair germ cells of telogen follicles and caused a rapid shift to the anagen phase. $^{13}$

Clinical trials in AGA patients treated with $2 \%$ or $5 \% \mathrm{MS}$ showed a remarkable increase in hair growth and decrease in hair loss, and superior results were evident with the 5\% formulation. ${ }^{14,15}$ Hypertrichosis in untreated areas suggested that the drug increased the anagen interval in humans. An experimental study showed that minoxidil prolonged the anagen phase in the dermal papilla (DP), by inducing $\beta$ catenin activity and stimulated follicular proliferation and differentiation. ${ }^{16}$ Histologically, an increase in follicle size and anagen follicle percentage were noted. ${ }^{17,18}$ 
Laser Doppler velocimetry revealed that minoxidil may have vascular effects. However, electron microscopy showed evidence of increased fenestration in the follicular capillary wall around anagen bulbs with $4 \% \mathrm{MS} .{ }^{19}$ Vascular endothelial growth factor (VEGF) in DP cells regulated perifollicular vascularization, as it increased strikingly during the anagen phase and declined during the catagen and telogen phases. ${ }^{20,21}$ Minoxidil increased VEGF mRNA expression in a dosedependent manner, where VEGF mRNA expression was increased by six times with the application of minoxidil. Furthermore, a recent study by Yum et al demonstrated that topical minoxidil induced hypoxia-inducible factor-1-alpha, which VEGF induction is dependent. ${ }^{22}$

Minoxidil also stimulated prostaglandin $\mathrm{E}_{2}$ production by activating prostaglandin endoperoxide synthase- $1^{23}$ but inhibited prostacyclin production. ${ }^{24}$ Additionally, expression of the prostaglandin $\mathrm{E}_{2}$ receptor, the most upregulated target gene in the $\beta$-catenin pathway of DP cells, was enhanced by minoxidil, which may enable hair follicles to grow continuously and maintain the anagen phase. ${ }^{25}$

\section{Use of minoxidil in hair disorders}

Topical minoxidil has been approved by the FDA for the treatment of AGA. Moreover, it has been used as an offlabel medication to treat several hair disorders such as alopecia areata (AA), scarring alopecia, and hair shaft disorders as well as to improve body hair growth in other areas including the eyebrows and beard (Table 1).

\section{Androgenetic alopecia}

AGA is a non-scarring alopecia in which terminal hairs transform into miniaturized hairs. Typically in men,

Table I The use of topical minoxidil in hair disorders

\begin{tabular}{|l|}
\hline FDA approved indications \\
\hline - Androgenetic alopecia \\
- Female pattern hair loss \\
\hline Off-label use \\
\hline - Alopecia areata \\
- Beard enhancement \\
- Central centrifugal cicatricial alopecia \\
- Chemotherapy-induced alopecia \\
- Eyebrow enhancement \\
- Frontal fibrosing alopecia \\
- Monilethrix \\
- Loose anagen hair syndrome \\
- Telogen effluvium \\
\hline
\end{tabular}

baldness occurs with frontal recession and vertex thinning, ${ }^{26}$ while in women, hair loss is characterized by a decrease in hair density over the crown without frontal hairline involvement, also known as female pattern hair loss (FPHL). ${ }^{27}$ Testosterone plays a role in AGA pathogenesis following conversion to dihydrotestosterone (DHT) by 5-alpha reductase. ${ }^{28,29}$

A meta-analysis showed that topical minoxidil at all concentrations provided superior results to those achieved in the placebo group. Regarding AGA, the study showed mean differences of 8.11 hairs $/ \mathrm{cm}^{2}$ and 14.90 hairs $/ \mathrm{cm}^{2}$ associated with the $2 \%$ and $5 \%$ minoxidil treatments, respectively, compared to the placebo group. While a comparison of the $2 \%$ minoxidil and placebo groups in female patients showed a mean difference of 12.41 hairs $/ \mathrm{cm}^{2} .{ }^{30} \mathrm{~A}$ 5 -year follow-up study in 31 AGA patients treated with $2 \%$ and $5 \%$ MS showed peak hair regrowth at 1 year. $^{31}$

Numerous clinical trials were conducted with topical minoxidil at several concentrations in different preparations to test the efficacy of the formulation. In men with AGA, 5\% MS demonstrated a significant increase in the mean difference in hair density compared with the $2 \%$ MS and placebo treatments. ${ }^{15,32,33}$ An earlier response was noted with $45 \%$ more hair regrowth in the $5 \%$ MS group than that in the $2 \%$ MS group at week 48 . Both $2 \%$ and $5 \%$ MS showed promising results in FPHL. However, side effects such as dermatitis, headaches, and hypertrichosis were more common with 5\% MS. Hypertrichosis could be problematic in women, leading to poor treatment compliance and, therefore, $2 \% \mathrm{MS}$ is preferable. ${ }^{34}$ Interestingly, $1 \%$ MS proved to be effective in Asian women, with a significant increase in non-vellus hair compared to that in the placebo group. ${ }^{35}$ Evidence from randomized controlled trials of topical minoxidil in AGA and FPHL is summarized in Tables 2 and 3, respectively.

The higher occurrence of contact dermatitis with MS led to the development of PG-free foam formulations to treat hair loss. In AGA patients, 5\% MF was well tolerated and superior to placebo. Only $5 \%$ of the patients experienced symptoms of scalp irritation after 52 weeks of treatment. ${ }^{32}$

For male AGA, the recommended treatment is twice daily application of $1 \mathrm{~mL} \mathrm{5 \%} \mathrm{MS} \mathrm{and} \mathrm{half} \mathrm{a} \mathrm{capful} \mathrm{of} \mathrm{5 \%}$ $\mathrm{MF}^{38}$ The treatment advised for FPHL is twice daily application of $1 \mathrm{~mL} 2 \% \mathrm{MS}$ and once daily application of half a capful of 5\% MF. Once daily topical application of $5 \% \mathrm{MF}$ has been proven to be as effective as twice daily application of $2 \%$ MS in FPHL with significantly fewer adverse events. ${ }^{36,37}$ Treatment should be continued 
Table 2 Randomized controlled trials in male androgenic alopecia

\begin{tabular}{|c|c|c|c|c|c|c|}
\hline $\begin{array}{l}\text { Author, } \\
\text { year }\end{array}$ & $\begin{array}{l}\text { Age, } \\
\text { years }\end{array}$ & Intervention group & Comparison & $\begin{array}{l}\text { Duration, } \\
\text { weeks }\end{array}$ & $\begin{array}{l}\text { Results, mean difference } \\
\text { hair density/ } \mathrm{cm}^{2} \text { (SD) } \\
\text { between baseline and } \\
\text { end of the study }\end{array}$ & Side effects \\
\hline $\begin{array}{l}\text { Olsen et al, } \\
2002^{15}\end{array}$ & $\begin{array}{l}36.5 \\
\text { (mean) }\end{array}$ & $\begin{array}{l}-2 \% \text { MS twice daily, } \\
N=|4| \\
\bullet 5 \% \text { MS twice daily, } \\
N=139\end{array}$ & $\begin{array}{l}\bullet \text { Placebo, } \\
\mathrm{N}=78\end{array}$ & 48 & $\begin{array}{l}\bullet 2 \% \text { MS: } 12.7(20.7) \\
\text { •5\% MS: } 18.6(25.4) \\
\text { •Placebo: } 3.9(21.7)\end{array}$ & $\begin{array}{l}\bullet 2 \% \text { MS: pruritus } 1 \% \text {, } \\
\text { headache } 0.6 \% \\
\text { - } 5 \% \text { MS: pruritus } 4 \% \text {, } \\
\text { headache } 3 \%\end{array}$ \\
\hline $\begin{array}{l}\text { Olsen et al, } \\
2007^{32}\end{array}$ & $\begin{array}{l}39.2 \\
\text { (mean) }\end{array}$ & $\begin{array}{l}\bullet 5 \% \text { MF twice daily, } \\
\mathrm{N}=180\end{array}$ & $\begin{array}{l}\bullet \text { Placebo, } \\
\mathrm{N}=172\end{array}$ & 16 & $\begin{array}{l}\text { •5\% MS: } 20.9 \text { (22.5) } \\
\text { •Placebo: } 4.7 \text { (19.7) }\end{array}$ & $\begin{array}{l}\text { Erythema } 3.9 \% \text {, dryness/ } \\
\text { scaling } 2.8 \% \text {, folliculitis } 1.1 \%\end{array}$ \\
\hline $\begin{array}{l}\text { Berger et al, } \\
2003^{33}\end{array}$ & $\begin{array}{l}40 \\
\text { (mean) }\end{array}$ & $\begin{array}{l}\bullet 5 \% \text { MS twice daily plus } \\
\text { placebo shampoo, } N=50\end{array}$ & $\begin{array}{l}\bullet \text { Placebo } \\
\text { shampoo, } \\
\mathrm{N}=50\end{array}$ & 26 & $\begin{array}{l}\bullet 5 \% \text { MS: } 12.3 \\
\text { •Placebo: }-0.58\end{array}$ & Local intolerance $7 \%$ \\
\hline
\end{tabular}

Abbreviations: MS, minoxidil solution; MF, minoxidil foam.

Table 3 Randomized controlled trials in female pattern hair loss

\begin{tabular}{|c|c|c|c|c|c|c|}
\hline $\begin{array}{l}\text { Author, } \\
\text { year }\end{array}$ & $\begin{array}{l}\text { Age, } \\
\text { years }\end{array}$ & $\begin{array}{l}\text { Intervention } \\
\text { group }\end{array}$ & Comparison & $\begin{array}{l}\text { Duration, } \\
\text { weeks }\end{array}$ & $\begin{array}{l}\text { Results, mean } \\
\text { difference hair densityl } \\
\mathrm{cm}^{2} \text { (SD) between } \\
\text { baseline and end of the } \\
\text { study }\end{array}$ & Side effects \\
\hline $\begin{array}{l}\text { Lucky et al, } \\
2004^{34}\end{array}$ & $\begin{array}{l}37 \\
\text { (mean) }\end{array}$ & $\begin{array}{l}\bullet 2 \% \mathrm{MS} \text { twice } \\
\text { daily, } \mathrm{N}=108 \\
\bullet 5 \% \mathrm{MS} \text { twice } \\
\text { daily, } \mathrm{N}=101\end{array}$ & $\begin{array}{l}- \text { Placebo, } \\
\mathrm{N}=5 \mathrm{I}\end{array}$ & 48 & $\begin{array}{l}\bullet 2 \% \text { MS: } 20.7 \text { (I7.6) } \\
\bullet 5 \% \text { MS: } 26.0 \text { (19.5) } \\
\text { •Placebo: } 9.4(14.6)\end{array}$ & $\begin{array}{l}\bullet 2 \% \text { MS: headache } 2 \% \text {, pruritus } 0.6 \% \\
\bullet 5 \% \text { MS: pruritus } 5 \% \text {, headache } 4 \% \text {, } \\
\text { hypertrichosis } 3 \%\end{array}$ \\
\hline $\begin{array}{l}\text { Tsuboi et al, } \\
2007^{35}\end{array}$ & $\begin{array}{l}\text { Over } \\
20\end{array}$ & $\begin{array}{l}\text { 1\% MS twice } \\
\text { daily, } N=120\end{array}$ & $\begin{array}{l}- \text { Placebo, } \\
\mathrm{N}=120\end{array}$ & 24 & $\begin{array}{l}\text { - I\% MS: } 8.15 \\
\text {-Placebo: } 2.03\end{array}$ & NA \\
\hline $\begin{array}{l}\text { Blume- } \\
\text { Pevtavi et al, } \\
2011^{36}\end{array}$ & $\begin{array}{l}49.9 \\
\text { (mean) }\end{array}$ & $\begin{array}{l}\bullet 5 \% \mathrm{MF} \text { once } \\
\text { daily, } \mathrm{N}=50\end{array}$ & $\begin{array}{l}\bullet 2 \% \mathrm{MS} \text { twice } \\
\text { daily, } \mathrm{N}=50\end{array}$ & 24 & $\begin{array}{l}\bullet 5 \% \text { MF: } 31.9 \text { (19.9) } \\
\bullet 2 \% \text { MS: } 28.4 \text { (19.9) }\end{array}$ & $\begin{array}{l}\bullet 5 \% \text { MF: facial hypertrichosis } 33 \% \text {, hair } \\
\text { shedding } 12.5 \% \text {, pruritus } 8.9 \% \text {, } \\
\text { dermatitis } 3.6 \% \text {, headache } 3.6 \% \text {, nausea } \\
\text { and breathlessness } 1.8 \% \text {, palpitation and } \\
\text { tachycardia } 1.8 \% \text {, papules and pustules } \\
\text { I.8\%, maculopapular rash } 1.8 \% \\
\bullet 2 \% \text { MS: facial hypertrichosis } 51 \% \text {, hair } \\
\text { shedding } 17.5 \% \text {, headache } 7 \% \text {, palpitation } \\
\text { and tachycardia } 3.5 \% \text {, ear swelling } 1.8 \% \text {, } \\
\text { papules and pustules } 1.8 \% \text {, dermatitis: } 1.8 \%\end{array}$ \\
\hline
\end{tabular}

Abbreviations: MS, minoxidil solution; MF, minoxidil foam; NA, not applicable.

indefinitely as termination of medication results in hair shedding within 3 to 4 months. Although there are limited data on teratogenicity, no serious adverse outcomes have been reported. As a safety measure, minoxidil should be avoided during pregnancy and lactation. ${ }^{39}$

The treatment response to topical minoxidil in AGA patients can be predicted by measuring sulfotransferase activity in plucked hair follicles. Studies have reported 93\% sensitivity and $83 \%$ specificity. ${ }^{40}$ The enzymatic assay also demonstrated great accuracy by correctly detecting $94 \%$ of non-responders. $^{41}$ A subsequent study using this assay showed that at the week 8 of topical minoxidil treatment, the sulfotransferase enzyme activity in hairs stabilized. This finding suggests that those who respond to minoxidil will not 
develop resistance to the existing dosage and, similarly, nonresponsive patients will not turn into responders. ${ }^{42}$ A study by McCoy et al demonstrated that an increase in topical minoxidil concentration up to $15 \%$ in patients predicted to be non-responders increased the clinical response compared to that associated with $5 \%$ minoxidil without cardiac side effects. ${ }^{43}$ Therefore, the non-responders may have a clinical response with increased concentration of minoxidil.

There has been an increase in the use of a novel formula, minoxidil sulfate-based solution (MXS) since it is an active metabolite of minoxidil. It has been proven that MXS has a higher efficacy than that of the conventional formula and might be an option for patients with low minoxidil sulfotransferase activity. ${ }^{16,44}$ However, because of its larger molecular weight, which affects its penetrability, and its higher degree of degradation than that of MS, MXS may not be as efficacious. ${ }^{45}$ To improve response, MXS should be applied at higher concentrations and the formulation should be kept in small package to decrease the instability of the solution. ${ }^{44}$ A study conducted in 44 patients with AGA and FPHL who did not show improvements with twice daily application of 5\% MS reported responsiveness to $10 \%$ MXS after treatment for 4 months. Side effects were tolerable irritation, erythema, and folliculitis. ${ }^{46}$ Therefore, we believe that MXS is a promising agent for those who are MS non-responders.

Attempts have been made to use oral minoxidil for AGA or FPHL patients who were not satisfied with conventional treatment. A combination of low-dose minoxidil $2.5 \mathrm{mg}$ and spironolactone $25 \mathrm{mg}$ in patients with FPHL showed preferable outcomes with decrease hair shedding and improved hair density. The mean severity score reduced to 2.3 at 6 months and 2.6 at 12 months. Mild adverse effects including urticaria, postural hypotension, and facial hypertrichosis were reported. No significant change in blood pressure was observed in the study. ${ }^{47}$

\section{Alopecia areata}

AA is an autoimmune disease of the hair follicles with a clinical presentation ranges from patchy non-scarring alopecia to complete scalp (alopecia totalis) and body (alopecia universalis) hair loss. ${ }^{48}$ There are many treatment modalities available; nonetheless, none has received FDA approval. Minoxidil is occasionally used off-label as monotherapy or in combination with other treatments. ${ }^{49,50}$

Minoxidil was initially tested in patients with AA, but there was a lack of satisfactory efficacy data. ${ }^{51}$ Monotherapy with topical minoxidil provided unsatisfactory outcomes as hair growth was stimulated only in cases of mild AA and not severe AA. Two randomized controlled trials demonstrated that treatment with $3 \%$ MS enhanced hair regrowth to some degree compared to placebo. Hair growth was detected earlier and became denser at the treated site, but slight to no effects were observed in patients with extensive AA. Only mild side effects of minoxidil were reported with no evidence of systemic effects. ${ }^{52,53}$ A higher concentration of topical minoxidil was preferable in AA treatment because of its dose-response effect. In extensive AA (more than 75\% scalp involvement), 5\% MS demonstrated $81 \%$ terminal hair regrowth versus $38 \%$ in $1 \%$ MS group. ${ }^{54}$ Moreover, Olsen et al demonstrated that a combination of prior systemic corticosteroid use (for more than 6 weeks) followed by $2 \%$ MS application (three times daily) provided a better outcome with persistent hair growth than without the combination. ${ }^{55}$

Histologic studies on the effect of minoxidil in AA demonstrated a decrease in perifollicular infiltration in respondents. ${ }^{56}$ Similar results were found with a significant reduction in perifollicular Langerhans cells and T cell infiltration in corresponding patients. ${ }^{57}$ In contrast to previous studies, no significant change in perifollicular infiltration was detected. ${ }^{58,59}$ Hence, the immunosuppressive effect of minoxidil is still unclear.

Collectively, many studies have suggested that topical minoxidil offered some benefits to AA patients as it slightly increased hair growth without altering disease progression or inducing remission. ${ }^{52}$ As a monotherapy, topical minoxidil treatment failed to demonstrate a statistically significant improvement. Thus, it has been recommended as an adjuvant therapy for AA. ${ }^{51}$

The use of oral minoxidil $5 \mathrm{mg}$ twice daily in 65 recalcitrant AA patients was studied. The medication was relatively tolerable with $2 \mathrm{~g}$ of strict sodium intake. Better hair regrowth rate was noted in patients treated with oral minoxidil than in patients treated with 5\% MS. However, only $18 \%$ of patients showed an improved cosmetic response at 34.8 weeks with a prominent increase in terminal hairs. Systemic symptoms of sodium and water retention developed in patients who did not adhere to the sodium restriction protocol. Other side effects included headache, palpitation, and facial hypertrichosis. ${ }^{60}$

\section{Chronic telogen effluvium}

Telogen effluvium is a common non-scarring alopecia characterized by excessive telogen hair shedding triggered by stressful events such as pregnancy, a major illness, and surgery. Chronic telogen effluvium (CTE) is defined as hair 
loss persisting over 6 months. ${ }^{61}$ Treatment for CTE can be frustrating and many medications have been tried, including minoxidil. There have been limited clinical trials on topical minoxidil use to treat telogen effluvium. However, oral minoxidil may be a promising treatment option. Recently, a retrospective review was conducted among 36 female patients with CTE treated daily with oral minoxidil at doses ranging from 0.25 to $2.5 \mathrm{mg}$. Marked reduction in hair shedding was observed at 6 and 12 months. Some patients demonstrated mild facial hypertrichosis, dizziness, and altered blood pressure as adverse events. ${ }^{62}$

\section{Scarring alopecia}

In scarring alopecia, medical treatment should be initiated as early as possible. The aim of the treatment is to preserve the remaining hair follicles and halt disease progression. ${ }^{63}$ Central centrifugal cicatricial alopecia is a common scarring alopecia among African American women. It usually presents with hair loss on the vertex and spreads toward the periphery. ${ }^{64}$ In one small retrospective study, a combination of high-potency topical steroids and topical minoxidil showed no significant improvement. However, a decrease in disease severity score in some patients might suggest that the medication can slow the course of the condition. ${ }^{65}$

Topical minoxidil has been used to treat frontal fibrosing alopecia (FFA), a scaring alopecia condition affecting the frontal and temporal hairlines. ${ }^{66}$ In a case review, 50\% of FFA patients $(n=7)$ cotreatment with $2 \%$ MS applied twice daily and systemic steroids or finasteride showed slow disease progression. ${ }^{67}$ Another type of scarring alopecia reported to be improved by topical minoxidil is traction alopecia. The characteristic feature of being non-scarring and reversible in the initial stages of the condition may benefit from minoxidil use. Two patients who did not respond to topical triamcinolone over 1 year experienced significant hair growth with $2 \%$ minoxidil alone. ${ }^{68}$ Thus, topical minoxidil could be helpful and may be used as an adjuvant with other drugs to treat scarring hair loss condition.

\section{Chemotherapy-induced alopecia}

Hair loss is one of the common side effects of chemotherapy. ${ }^{69}$ A randomized controlled trial conducted by Duvic et al showed that $1 \mathrm{~mL} 2 \%$ MS applied to the entire scalp twice daily shortened the duration of alopecia by approximately 50 days in patients (Table 4). The medication was used throughout and for up to 4 months after chemotherapy treatment. ${ }^{70}$ However, in several cases, MS failed to prevent hair loss in gynecologic malignancies and solid tumors treated with doxorubicin-based chemotherapy. ${ }^{71,72}$ Even in breast cancer patients who applied $1.5 \mathrm{~mL} \mathrm{5 \%} \mathrm{MS}$ twice daily, there was no satisfactory hair regrowth 6 months after the treatment. $^{73}$ Therefore, the true effectiveness of topical minoxidil in chemotherapy-induced alopecia has still not been demonstrated.

Low-dose oral minoxidil (1 mg once daily) might be a potential treatment for permanent chemotherapy-induced alopecia (PCIA). A patient diagnosed with acute myeloid leukemia who had PCIA for 16 months showed an increase in hair growth at 6 weeks. Significant hair regrowth with reemerged anagen follicles and decreased miniaturization was demonstrated histologically following 2 years of treatment. ${ }^{74}$

\section{Hair shaft disorders}

Minoxidil has been used to treat monilethrix, a rare autosomal dominant hair disorder manifested as fragile hair shafts with a regular beaded appearance. ${ }^{75}$ Four patients with monilethrix of the scalp who were treated with $1 \mathrm{~mL}$ $2 \%$ MS with twice daily application for 1 year showed an increase in normal hair growth in the affected areas at 6 and 12 months, and no one experienced adverse reactions. The effect seen might be due to anagen phase prolongation. $^{76}$ Topical minoxidil has also been reported to be effective in treating loose anagen hair syndrome (LAS). A 2-year-old girl with LAS who was treated with 5\% MS applied for 20 months showed significant improvement and the effect persisted 28 months after the cessation of medication. No adverse effects were noted. ${ }^{77}$

Oral minoxidil had been used in many cases of hair shaft disorders as topical minoxidil application may worsen hair shaft brittleness. ${ }^{78}$ A low dose of oral minoxidil $(0.25 \mathrm{mg}$ once daily) was administered to treat two patients with monilethrix. Promising results were seen in one case with reduced hair shedding, lengthened hair, and initial significant improvement in hair density in the 3rd and 6th month. Improvement in the hair condition was maintained with the same dosage after 18 to 24 months. No adverse event was observed. ${ }^{78}$ In another case, oral minoxidil was used for hair shaft disorder in a 6-year-old girl with LAS who did not respond to $5 \% \mathrm{MS}$. She received oral minoxidil $0.5 \mathrm{mg}$ daily and showed improvement in hair color, density, and length within 3 months of treatment. ${ }^{79}$

\section{Body hair enhancement}

Topical minoxidil has been employed to stimulate hair growth on eyebrows and beard growth (Table 4). Eyebrows serve an important role as periocular 
Table 4 Randomized controlled trials in non-AGA conditions

\begin{tabular}{|c|c|c|c|c|c|c|c|}
\hline Author, year & Condition & $\begin{array}{l}\text { Age, } \\
\text { years }\end{array}$ & $\begin{array}{l}\text { Intervention } \\
\text { group }\end{array}$ & Comparison & $\begin{array}{l}\text { Duration, } \\
\text { weeks }\end{array}$ & $\begin{array}{l}\text { Results, mean } \\
\text { difference hair } \\
\text { density/cm }{ }^{2}(\mathrm{SD}) \\
\text { between baseline } \\
\text { and end of the study }\end{array}$ & Side effects \\
\hline $\begin{array}{l}\text { Duvic M, } \\
1996^{70}\end{array}$ & $\begin{array}{l}\text { Chemotherapy- } \\
\text { induced } \\
\text { alopecia }\end{array}$ & $\begin{array}{l}44 \\
\text { (median) }\end{array}$ & $\begin{array}{l}-2 \% \mathrm{MS} \text { twice } \\
\text { daily, } \mathrm{N}=10\end{array}$ & $\begin{array}{l}- \text { Placebo, } \\
N=9\end{array}$ & $\begin{array}{l}\text { Until hair } \\
\text { regrowth was } \\
\text { dense enough } \\
\text { to be parted } \\
\text { (mean } \\
\text { I } 48.5 \text { days) }\end{array}$ & NA & $\begin{array}{l}\text { Pruritus } 60 \% \text {, } \\
\text { hypertrichosis } \\
38.1 \% \text {, scalp } \\
\text { folliculitis } 25 \%\end{array}$ \\
\hline $\begin{array}{l}\text { Lee et al, } \\
2014^{82}\end{array}$ & $\begin{array}{l}\text { Eyebrow } \\
\text { hypotrichosis }\end{array}$ & $\begin{array}{l}30.6 \\
\text { (mean) }\end{array}$ & $\begin{array}{l}\cdot 2 \% \mathrm{MS} \text { twice } \\
\text { daily, } \mathrm{N}=39\end{array}$ & $\begin{array}{l}\text {-Placebo, } \\
N=39\end{array}$ & 16 & $\begin{array}{l}\bullet 2 \% \text { MS: } 5.1 \text { (5.2) } \\
\text { •Placebo: } 1.0(4.7)\end{array}$ & $\begin{array}{l}\text { Mild-moderate } \\
\text { side effects } 12.8 \%\end{array}$ \\
\hline $\begin{array}{l}\text { Worapunpong } \\
\text { et al, } 2017^{83}\end{array}$ & $\begin{array}{l}\text { Eyebrow } \\
\text { hypotrichosis }\end{array}$ & $\begin{array}{l}30.7 \\
\text { (mean) }\end{array}$ & $\begin{array}{l}-1 \% \mathrm{MS} \text { twice } \\
\text { daily, } \mathrm{N}=40\end{array}$ & $\begin{array}{l}- \text { Placebo, } \\
\mathrm{N}=40\end{array}$ & 16 & $\begin{array}{l}\bullet \text { I\% MS: I0.5 (I5.0) } \\
\text { •Placebo: } 8.1 \text { (I0.6) }\end{array}$ & $\begin{array}{l}\text { Mild itching and } \\
\text { burning } 22.5 \%\end{array}$ \\
\hline $\begin{array}{l}\text { Ingprasert } \\
\text { et al, } 2016^{85}\end{array}$ & $\begin{array}{l}\text { Beard } \\
\text { enhancement }\end{array}$ & $\begin{array}{l}20-60 \\
\text { (range) }\end{array}$ & $\begin{array}{l}\bullet 3 \% \text { MS twice } \\
\text { daily, } N=23\end{array}$ & $\begin{array}{l}\text {-Placebo, } \\
\mathrm{N}=23\end{array}$ & 16 & $\begin{array}{l}\bullet 3 \% \text { MS: } 5.0(0.7) \\
\text { •Placebo: } 0.4(0.3)\end{array}$ & NA \\
\hline
\end{tabular}

Abbreviations: AGA, androgenetic alopecia; MS, minoxidil solution; MF, minoxidil foam; NA, not applicable.

landmarks on the face. Eyebrow hypotrichosis is a condition comprising a reduction in eyebrow density and a lack of growth. ${ }^{80,81} \mathrm{~A}$ recent 16 -week randomized controlled trial proved that twice daily application of $2 \% \mathrm{MS}$ was superior to placebo for eyebrow hypotrichosis treatment. ${ }^{82}$ Significant changes in the global photographic score were observed in the treatment group compared to those in the placebo group. Eyebrow density and diameter also increased significantly. Statistical differences in both subjective and objective assessment were noticed from week 8 to 16 . Similar results were also noted with $1 \%$ MS applied twice daily, with significant changes in global photographic scores, hair count, hair diameter, and patient satisfaction. ${ }^{83}$ Furthermore, MS 3\% was proven to be as effective as $0.03 \%$ topical bimatoprost for eyebrow enhancement. Nevertheless, contact dermatitis was more common in the $3 \% \mathrm{MS}$ group. ${ }^{84}$

Beard hair is a collection of hair on the chin that frames the facial appearance and symbolizes masculinity. Compared to placebo, minoxidil was superior in enhancing beard growth, with only mild adverse effects. Statistically significant differences in global photographic scores, hair count, and patients' selfassessment from baseline with twice daily application of $0.5 \mathrm{~mL}$ of $3 \%$ MS group were detected when compared to the placebo group. ${ }^{85}$ Hence, minoxidil was considered to be safe and beneficial for eyebrow and beard enhancement.

\section{Adverse effects of minoxidil}

Topical minoxidil has been considered safe; however, some patients experienced side effects after application. The most common side effect of MS is irritant contact dermatitis with the typical symptoms of itching and scaling. The incidence is lower with $2 \%$ MS than it is with 5\% MS. Allergic contact dermatitis can also occur because of PG or minoxidil itself. A patch test should be performed to determine the causative agents. Although an allergic reaction to minoxidil could occur, it is infrequent. If patients are allergic to PG, the vehicles should be substituted with butylene glycol, glycerin, or polysorbate. Moreover, MF, a PG-free formula, should be prescribed instead and if the reactions persist, then allergy to minoxidil should be suspected. In this scenario, the use of all minoxidil preparations should be discontinued. ${ }^{86}$

Hypertrichosis depends on minoxidil concentration, with the highest incidence of unwanted hair growth experienced by those treated with $5 \%$ MS. ${ }^{87}$ It occurs more commonly in female patients than in male patients and while there is no clear explanation, some female patients 
might have a higher number of minoxidil-sensitive follicles than others. Spontaneous resolution occurred first on the face and arms (1-3 months), followed by the legs (4-5 months) after minoxidil termination. It had been assumed that excessive topical application could induce systemic absorption, leading to excessive hair growth in non-treated areas. ${ }^{88,89}$ Twice daily application of topical minoxidil shows no systemic side effects such as hypotension, abnormal heart rate, and weight gain. ${ }^{2}$ It is considered safe and provides positive outcomes in various hair disorders.

Oral minoxidil is mostly metabolized via the liver by conjugation with glucuronic acid. The metabolized minoxidil is excreted through the kidneys $3-4$ hrs after administration, but the vasodilation property may persist for up to 72 hrs. $^{1}$ Serious adverse effects including sodium and fluid retention, and cardiovascular effects (eg ischemic heart disease, pericardial effusion, and pulmonary hypertension) have been reported with systemically administered minoxidil. ${ }^{12}$ Sodium and fluid retention causes a rise in body weight and in severe cases, congestive heart failure occurred. This is due to the redistribution of blood flow from the outer to the inner cortex of the kidney as well as plasma-renin activity. ${ }^{1,2}$ Ischemic heart disease was reported, which might have been due to higher oxygen demand as heart rate and cardiac output increased. ${ }^{4}$ Pericardial effusion caused by minoxidil occurs around $5 \%$ of patients with unknown mechanism. ${ }^{12}$ Pulmonary hypertension due to increased pulmonary artery pressure and high cardiac output from minoxidil has also been described. $^{12}$ Other adverse effects include hypertrichosis, occasional pulsating headache, itchy eyes, skin rashes such as bullous eruptions, and polymenorrhea. ${ }^{12,89,90}$ In our opinion, the benefits of the oral medication are not sufficient to justify exposure to the risk of potential side effects.

\section{Conclusion}

Minoxidil is a common medication prescribed for treating hair loss-related problems. It provides remarkable benefits to patients with hair disorders. To date, the FDA has approved minoxidil only for AGA. However, minoxidil is used off-label for treating several hair disorders as well as increasing body hair growth. Although topical minoxidil is considered an effective and safe treatment option for various hair disorders, additional evidencebased data are needed for some applications.

\section{Disclosure}

The authors report no conflicts of interest in this work.

\section{References}

1. Campese VM. Minoxidil: a review of its pharmacological properties and therapeutic use. Drugs. 1981;22(4):257-278. doi:10.2165/ 00003495-198122040-00001

2. Rossi A, Cantisani C, Melis L, Iorio A, Scali E, Calvieri S. Minoxidil use in dermatology, side effects and recent patents. Recent Pat Inflamm Allergy Drug Discov. 2012;6(2):130-136.

3. Tata S, Weiner N, Flynn G. Relative influence of ethanol and propylene glycol cosolvents on deposition of minoxidil into the skin. $J$ Pharm Sci. 1994;83(10):1508-1510. doi:10.1002/jps.2600831026

4. Gogtay JA, Panda M. Minoxidil topical foam: a new kid on the block. Int J Trichology. 2009;1(2):142. doi:10.4103/0974-7753.58560

5. Purnak T, Senel E, Sahin C. Liquid formulation of minoxidil versus its foam formulation. Indian $J$ Dermatol. 2011;56(4):462. doi:10.4103/0019-5154.84714

6. Shorter K, Farjo NP, Picksley SM, Randall VA. Human hair follicles contain two forms of ATP-sensitive potassium channels, only one of which is sensitive to minoxidil. Faseb J. 2008;22(6):1725-1736. doi:10.1096/fj.07-099424

7. Xu D, Wang L, Dai W, Lu L. A requirement for K+-channel activity in growth factor-mediated extracellular signal-regulated kinase activation in human myeloblastic leukemia ML-1 cells. Blood. 1999;94 (1):139-145.

8. Malhi H, Irani AN, Rajvanshi P, et al. KATP channels regulate mitogenically induced proliferation in primary rat hepatocytes and human liver cell lines. Implications for liver growth control and potential therapeutic targeting. J Biol Chem. 2000;275(34):26050-26057.

9. Buhl AE, Waldon DJ, Kawabe TT, Holland JM. Minoxidil stimulates mouse vibrissae follicles in organ culture. J Invest Dermatol. 1989;92 (3):315-320.

10. Anderson RJ, Kudlacek PE, Clemens DL. Sulfation of minoxidil by multiple human cytosolic sulfotransferases. Chem Biol Interact. 1998;109(1-3):53-67.

11. Goren A, Sharma A, Dhurat R, et al. Low-dose daily aspirin reduces topical minoxidil efficacy in androgenetic alopecia patients. Dermatol Ther. 2018;31(6):e12741. doi:10.1111/dth.12741

12. Lowenthal DT, Affrime MB. Pharmacology and pharmacokinetics of minoxidil. J Cardiovasc Pharmacol. 1980;2 Suppl 2:S93-S106. doi:10.1097/00005344-198000022-00002

13. Mori $\mathrm{O}$, Uno $\mathrm{H}$. The effect of topical minoxidil on hair follicular cycles of rats. J Dermatol. 1990;17(5):276-281.

14. Price VH, Menefee E, Strauss PC. Changes in hair weight and hair count in men with androgenetic alopecia, after application of $5 \%$ and $2 \%$ topical minoxidil, placebo, or no treatment. J Am Acad Dermatol. 1999;41(5 Pt 1):717-721. doi:10.1016/s0190-9622(99)70006-x

15. Olsen EA, Dunlap FE, Funicella T, et al. A randomized clinical trial of $5 \%$ topical minoxidil versus $2 \%$ topical minoxidil and placebo in the treatment of androgenetic alopecia in men. J Am Acad Dermatol. 2002;47(3):377-385. doi:10.1067/mjd.2002.124088

16. Messenger AG, Rundegren J. Minoxidil: mechanisms of action on hair growth. $B r J$ Dermatol. 2004;150(2):186-194. doi:10.1111/ j.1365-2133.2004.05785.x

17. Abell E. Histologic response to topically applied minoxidil in malepattern alopecia. Clin Dermatol. 1988;6(4):191-194.

18. Headington IT, Novak E. Clinical and histologic studies of male pattern baldness treated with topical minoxidil. Curr Ther Res. 1984;36:1098-1106.

19. Sakita S, Kagoura M, Toyoda M, Morohashi M. The induction by topical minoxidil of increased fenestration in the perifollicular capillary wall. Br J Dermatol. 1999;140(2):294-296. doi:10.1046/j.13652133.1999.02666.x 
20. Lachgar S, Charveron M, Gall Y, Bonafe JL. Minoxidil upregulates the expression of vascular endothelial growth factor in human hair dermal papilla cells. $B r \quad J$ Dermatol. 1998;138(3):407-411. doi:10.1046/j.1365-2133.1998.02115.x

21. Yano K, Brown LF, Detmar M. Control of hair growth and follicle size by VEGF-mediated angiogenesis. J Clin Invest. 2001;107 (4):409-417. doi:10.1172/JCI11317

22. Yum S, Jeong S, Kim D, et al. Minoxidil Induction of VEGF is mediated by inhibition of HIF-Prolyl hydroxylase. Int $\mathrm{J} \mathrm{Mol} \mathrm{Sci}$. 2017;19(1). doi:10.3390/ijms19010053

23. Michelet JF, Commo S, Billoni N, Mahe YF, Bernard BA. Activation of cytoprotective prostaglandin synthase-1 by minoxidil as a possible explanation for its hair growth-stimulating effect. $J$ Invest Dermatol. 1997;108(2):205-209. doi:10.1111/1523-1747.ep12334249

24. Kvedar JC, Baden HP, Levine L. Selective inhibition by minoxidil of prostacyclin production by cells in culture. Biochem Pharmacol. 1988;37(5):867-874. doi:10.1016/0006-2952(88)90174-8

25. Shin H, Kwack MH, Shin SH, et al. Identification of transcriptional targets of Wnt/beta-catenin signaling in dermal papilla cells of human scalp hair follicles: EP2 is a novel transcriptional target of Wnt3a. $J$ Dermatol Sci. 2010;58(2):91-96. doi:10.1016/j.jdermsci.2010.02.011

26. Suchonwanit P, Srisuwanwattana P, Chalermroj N, Khunkhet S. A randomized, double-blind controlled study of the efficacy and safety of topical solution of $0.25 \%$ finasteride admixed with $3 \%$ minoxidil vs. $3 \%$ minoxidil solution in the treatment of male androgenetic alopecia. J Eur Acad Dermatol Venereol. 2018;32(12):2257-2263. doi: $10.1111 /$ jdv. 15171

27. Suchonwanit P, Iamsumang W, Rojhirunsakool S. Efficacy of topical combination of $0.25 \%$ finasteride and $3 \%$ minoxidil versus $3 \%$ minoxidil solution in female pattern hair loss: a randomized, doubleblind, controlled study. Am J Clin Dermatol. 2019;20(1):147-153. doi:10.1007/s40257-018-0387-0

28. Rojhirunsakool S, Suchonwanit P. Parietal scalp is another affected area in female pattern hair loss: an analysis of hair density and hair diameter. Clin Cosmet Investig Dermatol. 2018;11:7-12. doi: $10.2147 /$ CCID.S153768

29. Cotsarelis G, Millar SE. Towards a molecular understanding of hair loss and its treatment. Trends Mol Med. 2001;7(7):293-301.

30. Adil A, Godwin M. The effectiveness of treatments for androgenetic alopecia: a systematic review and meta-analysis. $J$ Am Acad Dermatol. 2017;77(1):136-141.e135. doi:10.1016/j.jaad.2017.02.054

31. Olsen EA, Weiner MS, Amara IA, DeLong ER. Five-year follow-up of men with androgenetic alopecia treated with topical minoxidil. $J$ Am Acad Dermatol. 1990;22(4):643-646. doi:10.1016/0190-9622(90)70089-z

32. Olsen EA, Whiting D, Bergfeld W, et al. A multicenter, randomized, placebo-controlled, double-blind clinical trial of a novel formulation of $5 \%$ minoxidil topical foam versus placebo in the treatment of androgenetic alopecia in men. $J$ Am Acad Dermatol. 2007;57 (5):767-774. doi:10.1016/j.jaad.2007.04.012

33. Berger RS, Fu JL, Smiles KA, et al. The effects of minoxidil, $1 \%$ pyrithione zinc and a combination of both on hair density: a randomized controlled trial. $\mathrm{Br} J$ Dermatol. 2003;149(2):354-362. doi:10.1046/j.1365-2133.2003.05435.x

34. Lucky AW, Piacquadio DJ, Ditre CM, et al. A randomized, placebocontrolled trial of $5 \%$ and $2 \%$ topical minoxidil solutions in the treatment of female pattern hair loss. J Am Acad Dermatol. 2004;50 (4):541-553. doi:10.1016/j.jaad.2003.06.014

35. Tsuboi R, Tanaka T, Nishikawa T, et al. A randomized, placebocontrolled trial of $1 \%$ topical minoxidil solution in the treatment of androgenetic alopecia in Japanese women. Eur J Dermatol. 2007;17 (1):37-44. doi:10.1684/ejd.2007.0187

36. Blume-Peytavi U, Hillmann K, Dietz E, Canfield D, Garcia Bartels N. A randomized, single-blind trial of $5 \%$ minoxidil foam once daily versus $2 \%$ minoxidil solution twice daily in the treatment of androgenetic alopecia in women. $J$ Am Acad Dermatol. 2011;65(6):11261134.e1122. doi:10.1016/j.jaad.2010.09.724
37. Blume-Peytavi U, Shapiro J, Messenger AG, et al. Efficacy and safety of once-daily minoxidil foam $5 \%$ versus twice-daily minoxidil solution $2 \%$ in female pattern hair loss: a Phase III, randomized, investigator-blinded study. J Drugs Dermatol. 2016;15(7):883-889.

38. Kelly Y, Blanco A, Tosti A. Androgenetic alopecia: an update of treatment options. Drugs. 2016;76(14):1349-1364. doi:10.1007/ s40265-016-0629-5

39. American Academy of Pediatrics Committee on Drugs. The transfer of drugs and other chemicals into human milk. Pediatrics. 2001;108 (3):776-789. doi:10.1542/peds.108.3.776

40. Roberts J, Desai N, McCoy J, Goren A. Sulfotransferase activity in plucked hair follicles predicts response to topical minoxidil in the treatment of female androgenetic alopecia. Dermatol Ther. 2014;27 (4):252-254. doi: $10.1111 /$ dth. 12130

41. Goren A, Shapiro J, Roberts J, et al. Clinical utility and validity of minoxidil response testing in androgenetic alopecia. Dermatol Ther. 2015;28(1):13-16. doi:10.1111/dth.12164

42. Goren A, McCoy J, Kovacevic M, et al. The effect of topical minoxidil treatment on follicular sulfotransferase enzymatic activity. J Biol Regul Homeost Agents. 2018;32(4):937-940.

43. McCoy J, Goren A, Kovacevic M, Shapiro J. Minoxidil dose response study in female pattern hair loss patients determined to be non-responders to 5\% topical minoxidil. J Biol Regul Homeost Agents. 2016;30(4):1153-1155.

44. Goren A, Castano JA, McCoy J, Bermudez F, Lotti T. Novel enzymatic assay predicts minoxidil response in the treatment of androgenetic alopecia. Dermatol Ther. 2014;27(3):171-173. doi:10.1111/dth.12111

45. Godin B, Touitou E. Transdermal skin delivery: predictions for humans from in vivo, ex vivo and animal models. Adv Drug Deliv Rev. 2007;59(11):1152-1161. doi:10.1016/j.addr.2007.07.004

46. Dias PCR, Miot HA, Trueb RM, Ramos PM. Use of minoxidil sulfate versus minoxidil base in androgenetic alopecia treatment: friend or foe? Skin Appendage Disord. 2018;4(4):349-350. doi:10.1159/ 000488011

47. Sinclair RD. Female pattern hair loss: a pilot study investigating combination therapy with low-dose oral minoxidil and spironolactone. Int J Dermatol. 2018;57(1):104-109. doi:10.1111/ijd.13838

48. Sriphojanart T, Khunkhet S, Suchonwanit P. A retrospective comparative study of the efficacy and safety of two regimens of diphenylcyclopropenone in the treatment of recalcitrant alopecia areata. Dermatol Rep. 2017;9(2):7399. doi:10.4081/dr.2017.7399

49. Triyangkulsri K, Suchonwanit P. Role of janus kinase inhibitors in the treatment of alopecia areata. Drug Des Devel Ther. 2018;12:2323-2335. doi:10.2147/DDDT.S172638

50. Gupta AK, Carviel J, Abramovits W. Treating alopecia areata: current practices versus new directions. Am J Clin Dermatol. 2017;18(1):6775. doi:10.1007/s40257-016-0230-4

51. Strazzulla LC, Wang EHC, Avila L, et al. Alopecia areata: an appraisal of new treatment approaches and overview of current therapies. J Am Acad Dermatol. 2018;78(1):15-24. doi:10.1016/j. jaad.2017.04.1142

52. Price VH. Double-blind, placebo-controlled evaluation of topical minoxidil in extensive alopecia areata. $J$ Am Acad Dermatol. 1987;16(3 Pt 2):730-736. doi:10.1016/s0190-9622(87)70095-4

53. Price VH. Topical minoxidil $(3 \%)$ in extensive alopecia areata, including long-term efficacy. $J$ Am Acad Dermatol. 1987;16(3 Pt 2):737-744. doi:10.1016/s0190-9622(87)70096-6

54. Fiedler-Weiss VC. Topical minoxidil solution $(1 \%$ and $5 \%)$ in the treatment of alopecia areata. J Am Acad Dermatol. 1987;16(3 Pt 2):745-748. doi:10.1016/s0190-9622(87)80003-8

55. Olsen EA, Carson SC, Turney EA. Systemic steroids with or without $2 \%$ topical minoxidil in the treatment of alopecia areata. Arch Dermatol. 1992;128(11):1467-1473.

56. Weiss VC, West DP. Topical minoxidil therapy and hair regrowth. Arch Dermatol. 1985;121(2):191-192. 
57. Fiedler VC, Buys CM. Immunohistochemical characterization of the cellular infiltrate in severe alopecia areata before and after minoxidil treatment. Dermatologica. 1987;175 Suppl 2:29-35.

58. Ranchoff RE, Bergfeld WF, Steck WD, Subichin SJ. Extensive alopecia areata. Results of treatment with 3\% topical minoxidil. Cleve Clin J Med. 1989;56(2):149-154.

59. Khoury EL, Price VH, Abdel-Salam MM, Stern M, Greenspan JS. Topical minoxidil in alopecia areata: no effect on the perifollicular lymphoid infiltration. $J$ Invest Dermatol. 1992;99(1):40-47. doi:10.1111/1523-1747.ep12611409

60. Fiedler-Weiss VC, Rumsfield J, Buys CM, West DP, Wendrow A. Evaluation of oral minoxidil in the treatment of alopecia areata. Arch Dermatol. 1987;123(11):1488-1490.

61. Harrison S, Sinclair R. Telogen effluvium. Clin Exp Dermatol. 2002;27(5):385-389.

62. Perera E, Sinclair R. Treatment of chronic telogen effluvium with oral minoxidil: a retrospective study. F1000Res. 2017;6:1650. doi:10.12688/f1000research.10493.2

63. Harnchoowong S, Suchonwanit P. PPAR-gamma agonists and their role in primary cicatricial alopecia. PPAR Res. 2017;2017:2501248. doi: $10.1155 / 2017 / 2501248$

64. Suchonwanit P, Hector CE, Bin Saif GA, McMichael AJ. Factors affecting the severity of central centrifugal cicatricial alopecia. Int $J$ Dermatol. 2016;55(6):e338-e343.

65. Eginli A, Dothard E, Bagayoko CW, Huang K, Daniel A, McMichael AJ. A retrospective review of treatment results for patients with central centrifugal cicatrical alopecia. J Drugs Dermatol. 2017;16(4):317-320.

66. Fertig R, Tosti A. Frontal fibrosing alopecia treatment options. Intractable Rare Dis Res. 2016;5(4):314-315.

67. Tosti A, Piraccini BM, Iorizzo M, Misciali C. Frontal fibrosing alopecia in postmenopausal women. $J$ Am Acad Dermatol. 2005;52 (1):55-60.

68. Khumalo NP, Ngwanya RM. Traction alopecia: $2 \%$ topical minoxidil shows promise. Report of two cases. J Eur Acad Dermatol Venereol. 2007;21(3):433-434.

69. Suchonwanit P, McMichael AJ. Alopecia in association with malignancy: a review. Am J Clin Dermatol. 2018;19(6):853-865.

70. Duvic M, Lemak NA, Valero V, et al. A randomized trial of minoxidil in chemotherapy-induced alopecia. J Am Acad Dermatol. 1996;35(1):74-78.

71. Granai CO, Frederickson H, Gajewski W, Goodman A, Goldstein A, Baden $\mathrm{H}$. The use of minoxidil to attempt to prevent alopecia during chemotherapy for gynecologic malignancies. Eur J Gynaecol Oncol. 1991;12(2):129-132.

72. Rodriguez R, Machiavelli M, Leone B, et al. Minoxidil (Mx) as a prophylaxis of doxorubicin-induced alopecia. Ann Oncol. 1994;5(8):769-770.

73. Prevezas C, Matard B, Pinquier L, Reygagne P. Irreversible and severe alopecia following docetaxel or paclitaxel cytotoxic therapy for breast cancer. Br J Dermatol. 2009;160(4):883-885.

74. Yang X, Thai KE. Treatment of permanent chemotherapy-induced alopecia with low dose oral minoxidil. Australas J Dermatol. 2016;57(4):e130-e132.
75. Djabali K, Panteleyev AA, Lalin T, et al. Recurrent missense mutations in the hair keratin gene hHb6 in monilethrix. Clin Exp Dermatol. 2003;28(2):206-210.

76. Rossi A, Iorio A, Scali E, et al. Monilethrix treated with minoxidil. Int J Immunopathol Pharmacol. 2011;24(1):239-242.

77. Chandran NS, Oranje AP. Minoxidil 5\% solution for topical treatment of loose anagen hair syndrome. Pediatr Dermatol. 2014;31 (3):389-390.

78. Sinclair R. Treatment of monilethrix with oral minoxidil. JAAD Case Rep. 2016;2(3):212-215.

79. Cranwell WC, Sinclair R. Loose anagen hair syndrome: treatment with systemic minoxidil characterised by marked hair colour change. Australas J Dermatol. 2018;59(4):e286-e287.

80. Chanasumon N, Sriphojanart T, Suchonwanit P. Therapeutic potential of bimatoprost for the treatment of eyebrow hypotrichosis. Drug Des Devel Ther. 2018;12:365-372.

81. Suchonwanit P, Chanasumon N, Sriphojanart T. Efficacy and safety of bimatoprost $0.01 \%$ for the treatment of eyebrow hypotrichosis: a randomized, double-blind, vehicle-controlled study. Dermatol Surg. 2019. doi:10.1097/DSS.0000000000001944

82. Lee S, Tanglertsampan C, Tanchotikul M, Worapunpong N. Minoxidil 2\% lotion for eyebrow enhancement: a randomized, double-blind, placebo-controlled, spilt-face comparative study. $J$ Dermatol. 2014;41(2):149-152.

83. Worapunpong N, Tanglertsampan C. Treatment of eyebrow hypotrichosis with $1 \%$ minoxidil lotion: a prospective, randomized, double-blind, placebo-controlled trial. J Med Assoc Thai. 2017;100(5):574-577.

84. Suwanchatchai W, Tanglertsampan C, Pengsalae N, Makornwattana M. Efficacy and safety of bimatoprost $0.03 \%$ versus minoxidil $3 \%$ in enhancement of eyebrows: a randomized, double-blind, split-face comparative study. J Dermatol. 2012;39(10):865-866.

85. Ingprasert S, Tanglertsampan C, Tangphianphan N, Reanmanee C. Efficacy and safety of minoxidil $3 \%$ lotion for beard enhancement: a randomized, double-masked, placebo-controlled study. J Dermatol. 2016;43(8):968-969.

86. Friedman ES, Friedman PM, Cohen DE, Washenik K. Allergic contact dermatitis to topical minoxidil solution: etiology and treatment. $J$ Am Acad Dermatol. 2002;46(2):309-312.

87. Dawber RP, Rundegren J. Hypertrichosis in females applying minoxidil topical solution and in normal controls. J Eur Acad Dermatol Venereol. 2003;17(3):271-275.

88. Peluso AM, Misciali C, Vincenzi C, Tosti A. Diffuse hypertrichosis during treatment with 5\% topical minoxidil. Br J Dermatol. 1997;136 (1):118-120.

89. Rogers NE, Avram MR. Medical treatments for male and female pattern hair loss. J Am Acad Dermatol. 2008;59(4):547-566; quiz 567-548.

90. Earhart RN, Ball J, Nuss DD, Aeling JL. Minoxidil-induced hypertrichosis: treatment with calcium thioglycolate depilatory. South Med J. 1977;70(4):442-443.

\section{Publish your work in this journal}

Drug Design, Development and Therapy is an international, peerreviewed open-access journal that spans the spectrum of drug design and development through to clinical applications. Clinical outcomes, patient safety, and programs for the development and effective, safe, and sustained use of medicines are a feature of the journal, which has also been accepted for indexing on PubMed Central. The manuscript management system is completely online and includes a very quick and fair peer-review system, which is all easy to use. Visit http://www. dovepress.com/testimonials.php to read real quotes from published authors. 